\begin{tabular}{|c|c|c|c|c|c|}
\hline \multicolumn{5}{|c|}{ REPORT DOCUMENTATION PAGE } & $\begin{array}{l}\text { Form Approved } \\
\text { OMB No. 0704-0188 }\end{array}$ \\
\hline \multicolumn{6}{|c|}{ 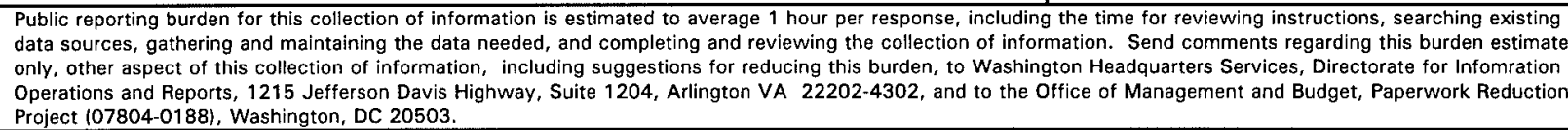 } \\
\hline \multicolumn{2}{|c|}{ 1. AGENCY USE ONLY (LEAVE BLANK) } & \multicolumn{2}{|c|}{$\begin{array}{l}\text { 2. REPORT DATE } \\
3 \text { August } 1995\end{array}$} & \multicolumn{2}{|c|}{$\begin{array}{l}\text { 3. REPORT TYPE AND DATES COVERED } \\
\text { Professional Paper }\end{array}$} \\
\hline $\begin{array}{l}\text { 4. TITLE AND SL } \\
\text { U.S. Navy T-45A }\end{array}$ & ure and Spir & raluation & \multicolumn{3}{|c|}{ 5. FUNDING NUMBERS } \\
\hline \multicolumn{6}{|c|}{$\begin{array}{l}\text { 6. AUTHOR(S) } \\
\text { Major Joseph A. Mortensen, USMC }\end{array}$} \\
\hline \multicolumn{3}{|c|}{$\begin{array}{l}\text { 7. PERFORMING ORGANIZATION NAME(S) } \\
\text { AND ADDRESS(ES) } \\
\text { Visual and Technical Information Branch } \\
\text { 7.2.4.3.A, Mail Stop 2, Bldg. } 405 \\
\text { Naval Air Warfare Center Aircraft Division } \\
\text { Patuxent River, Maryland 20670-5304 }\end{array}$} & \multicolumn{3}{|c|}{$\begin{array}{l}\text { 8. PERFORMING ORGANIZATION RERORI } \\
\text { NUMBER }\end{array}$} \\
\hline \multicolumn{3}{|c|}{$\begin{array}{l}\text { 9. SPONSORING/MONITORING AGENCY } \\
\text { NAME(S) AND ADDRESS(ES) } \\
\text { Naval Air Systems Command }\end{array}$} & \multicolumn{3}{|c|}{$\begin{array}{l}\text { 10. SPONSORINGIVIOINITORIING } \\
\text { AGENCY REPORT NUMBER }\end{array}$} \\
\hline \multicolumn{6}{|c|}{ 11. SUPPLEMENTARY NOTES } \\
\hline \multicolumn{5}{|c|}{$\begin{array}{l}\text { 12a. DISTRIBUTION/AVAILABILITY STATEMENT } \\
\text { Approved for public release, distribution is unlimited. }\end{array}$} & $\begin{array}{l}\text { 12b. DISTRIBUTION } \\
\text { CODE }\end{array}$ \\
\hline \multicolumn{6}{|c|}{$\begin{array}{l}\text { Approved for public release, distribution is unlimited. } \\
\text { 13. ABSTRACT (Maximum } 200 \text { words) }\end{array}$} \\
\hline \multirow{2}{*}{\multicolumn{3}{|c|}{$\begin{array}{l}\text { 14. SUBJECT TERMS } \\
\text { Combat System Test Bed;R\&D,Mobile } \\
\text { Demonstration }\end{array}$}} & \multicolumn{3}{|c|}{ 15. NUMBER OF PAGES 32} \\
\hline & & & \multicolumn{3}{|c|}{ 16. PRICE CODE } \\
\hline $\begin{array}{l}17 . \text { SECURITY } \\
\text { CLASSIFICATION OF } \\
\text { REPORT } \\
\text { UNCLASSIFIED }\end{array}$ & $\begin{array}{l}\text { 18. SECURI } \\
\text { CLASSIFICA } \\
\text { PAGE } \\
\text { UNCLASS }\end{array}$ & OF THIS & \multicolumn{2}{|c|}{$\begin{array}{l}\text { 19.SECURITY } \\
\text { CLASSIFICATION OF } \\
\text { ABSTRACT } \\
\text { N/A }\end{array}$} & $\begin{array}{l}\text { 20. LIMITATION OF } \\
\text { ABSTRACT } \\
\text { N/A }\end{array}$ \\
\hline
\end{tabular}




\section{U.S. NAVY T-45A DEPARTURE AND SPIN EVALUATION}

by

Major Joseph A. Mortensen, USMC

T-45 Project Coordination office

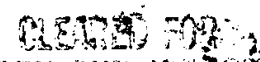

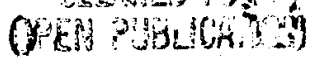

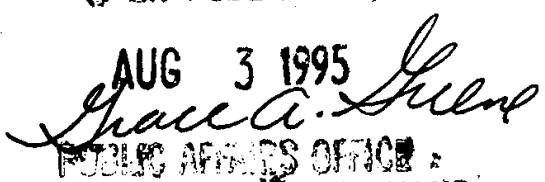

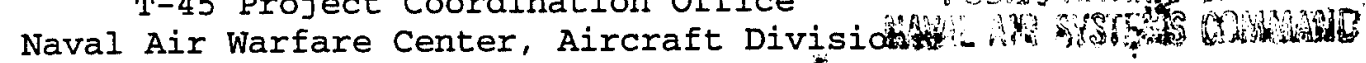
Patuxent River, Maryland U.S.A.

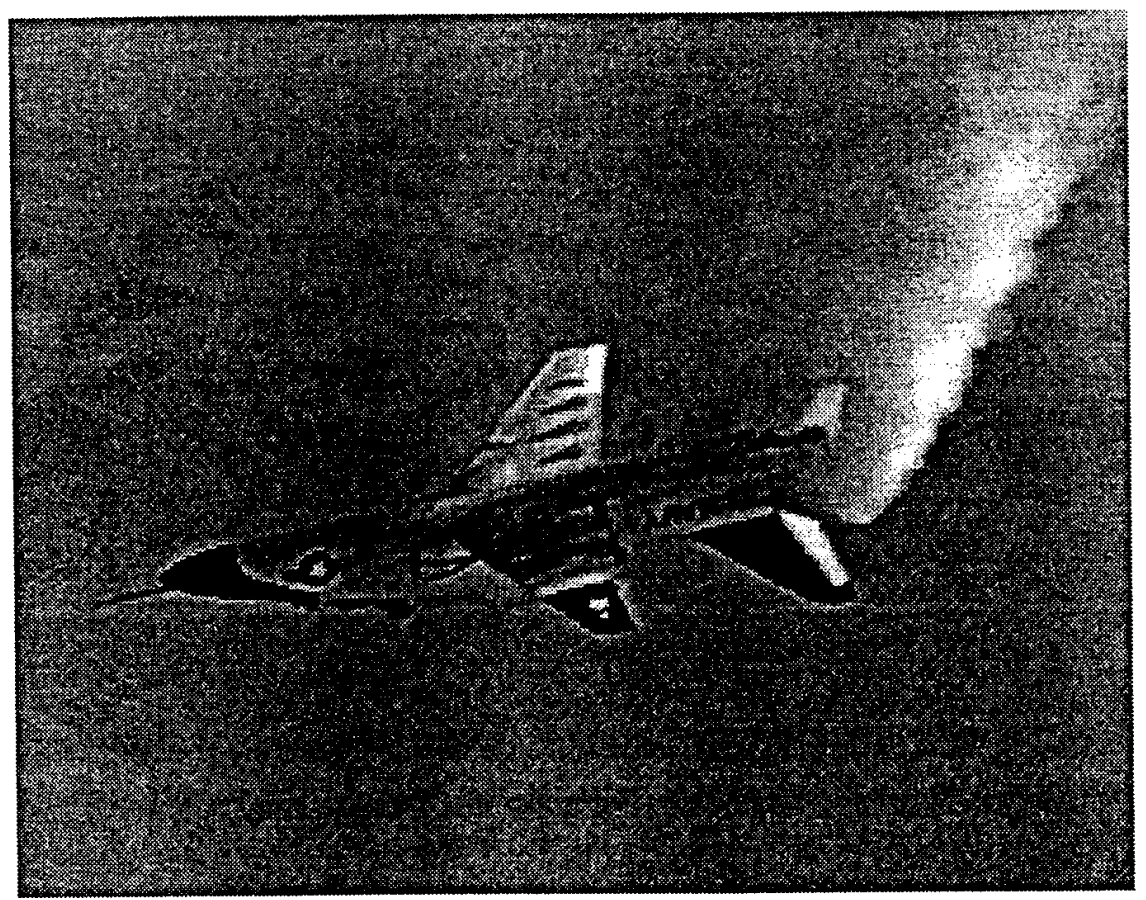

\section{ABSTRACT}

U. S. Navy T-45A departure and spin evaluation was conducted from $8 \mathrm{July}$ to 30 September 1994. The initial T-45A flight manual departure and spin recovery procedures evaluated proved unsatisfactory in providing consistent recoveries from inverted spin modes. Specifically, the procedures allowed the rudder to blow-out in the pro-spin direction during recovery, resulting in spin mode transitions and delayed recoveries. Furthermore, a third sustained inverted spin mode was discovered during flight tests. The initial flight manual procedures were successfully modified to reduce the occurrence of rudder blow-out during recovery attempts and provided more consistent recovery characteristics. 


\section{INTRODUCTION}

The T-45A Goshawk jet trainer is currently being phased in as the U.S. Navy's replacement for the aging T-2C and TA-4J aircraft. Navy High Angle-of-Attack (HAOA) testing of the T-45A was required and the Naval Air warfare Center, Aircraft Division (NAWC-AD) was tasked to conduct the testing.

The initial T-45A flight manual departure and spin recovery procedures evaluated proved unsatisfactory in providing consistent recoveries from inverted spin modes. Specifically, the procedures allowed the rudder to blow-out in the pro-spin direction during recovery, resulting in mode transitions and delayed recoveries. Additionally, a third sustained inverted spin mode was discovered during flight tests. The initial flight manual procedure was successfully modified to reduce the occurrence of rudder blow-out during recovery attempts and provided more consistent recovery characteristics. On two occasions during the evaluation, the test team elected to halt testing until data review provided answers to technically challenging questions arising from aerodynamic peculiarities of the T-45A.

This paper will highlight the results from the U. S. Navy evaluation of the T-45A departure, spin, and spin recovery characteristics and should provide a good example of a technically sound approach to a high risk test program and military and contractor test team integration.

\section{BACKGROUND}

Initial contractor (McDonnell Douglas Aerospace) T-45A High Angle-of-Attack (HAOA) testing began in January 1992 after spin chute and emergency systems functional tests. These tests were to demonstrate the high angle-of-attack and spin characteristics of the T-45A airplane as part of Full Scale Development (FSD). From January 1993 to April 1993 the contractor demonstrated two oscillatory divergent upright spin modes at $+30^{\circ}$ and $+45^{\circ} \mathrm{AOA}$ and two steady inverted spin modes at $-25^{\circ}$ and $-60^{\circ} \mathrm{AOA}$. Contractor testing was conducted intermittently until April 7, 1993 when the MDA test pilot, at $1,500 \mathrm{ft}-1 \mathrm{~b}_{\mathrm{f}}(2,034 \mathrm{~N}-\mathrm{m})$ of lateral asymmetry, encountered an inverted spin mode, $-25^{\circ}$ mode, that did not appear to respond to the current recovery controls and necessitated deployment of the anti-spin parachute. The anti-spin chute failed structurally and did not aid in recovery of the aircraft. The aircraft eventually recovered, after a total of 17 turns, when all controls were neutralized as the aircraft passed through the ejection altitude of 10,000 feet $(3,050 \mathrm{~m})$ above ground. This maneuver and additional analysis, indicated that the $-25^{\circ}$ inverted spin mode was potentially unrecoverable. A determination was made not to conduct additional departure nor inverted spin testing until

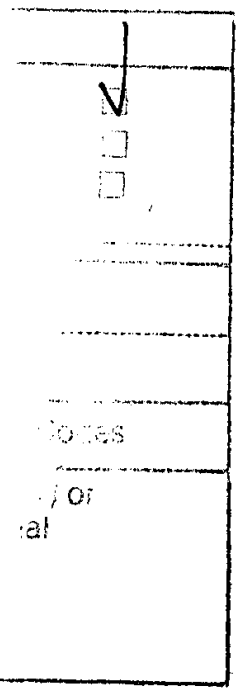


additional rotary balance wind tunnel data were gathered following Engineering Manufacturing Development (EMD). During Navy HAOA Developmental Testing in September and October 1993 no intentional departures nor spins were performed.

Following this initial testing, extensive rotary balance wind tunnel data were obtained in the inverted $\mathrm{AOA}$ region of the envelope. Using the $\mathrm{T}-45 \mathrm{~A}$ six degree-of-freedom simulation incorporating the rotary balance data, MDA identified recovery controls for all known inverted spin modes. As a result of the new information and procedures, the Naval Air Warfare Center, Aircraft Division, Patuxent River, Naval Air warfare command to
Maryland was tasked by the Naval Air Systems Comm
conduct a combined evaluation with the contractor, MDA, to validate the flight manual departure and spin recovery procedures and evaluate the departure and spin characteristics of the T-45A. This testing was conducted at Edwards AFB, California from 8 July to 30 september 1994.

\section{THE TEST AIRPLANE}

The T-45A Goshawk (see Figure 1), manufactured by MDA trainer currently being phased in as the U.S. Navy's trainer currently being phased In $\mathrm{TA}-4 \mathrm{~J}$ aircraft. Its design
replacement for the aging $\mathrm{T}-2 \mathrm{C}$ and $\mathrm{T}$.
is based on the British Aerospace HAWK. The T-45A is a low wing, tandem seat, single engine aircraft designed for shorebased and carrier-based operations. The test article BuNo 163599 (T003) was powered by an instrumented production Rolls Royce F405-RR-401 turbofan engine which was capable of producing $5,5271 \mathrm{~b}_{\mathrm{f}}(24,585 \mathrm{~N})$ of installed thrust at static,

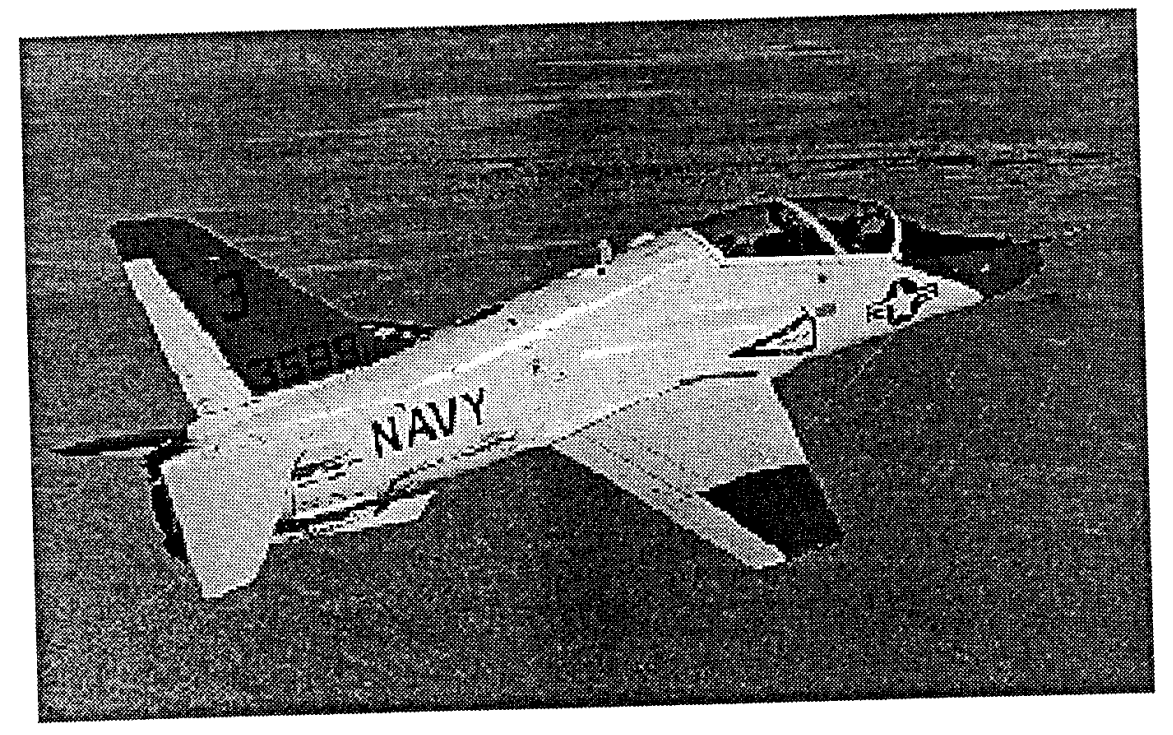

Figure 1. T-45A Aircraft. 
sea level, standard day conditions. The zero fuel weight of the test airplane was approximately $11,000 \mathrm{lb}(4,990 \mathrm{~kg})$ and was capable of carrying $440 \mathrm{gal}(1,6651)$ of fuel. The $24^{\circ}$ swept, laminar flow, transonic wing had full span leading edge slats and double slotted flaps along the trailing edge, a row of 20 vortex generators near the quarter chord and a six inch stall strip on the leading edge sixteen inches from the wing root. The primary flight control system consisted of and $10^{\circ}$ anhedral horizontal stabilator, hydraulically powered ailerons, and a reversible rudder with a no-float mechanism designed to maintain the rudder within $3^{\circ}$ to $4^{\circ}$ of neutral when no pilot input was commanded. The rudder was designed to break out of the no-float with a maximum rudder pedal input of $13 \mathrm{lb}_{\mathrm{f}}(58 \mathrm{~N})$. A yaw damper controller (YDC) provided slow speed (<217 KIAS) turn coordination, yaw damping, rudder trim, and a speed brake-to-stabilizer interconnect (SBI). The two speed brakes were located on each side of the fuselage just forward of the horizontal stabilator.

\section{MODIFICATIONS}

This airplane was considered production representative for the test, however, the test aircraft was extensively for the test, however, the margin of safety, pilot situational
modified to increase the mates
awareness and data gathering during the HAOA testing. These modifications included changes to the cockpit, hydraulic system, electrical system, oxygen system, fuel system, propulsion system, and the addition of an anti-spin parachute (spin chute) assembly.

In addition to a supplemental torso restraint installation, the modifications to the forward cockpit made to improve pilot situational awareness are shown in Figure 2 .

Early during testing, the flight test airspeed indicator was replaced by a production airspeed indicator. This was due to the large fluctuations in the flight test airspeed indicator needle during spins rendering the indicator

useless. Aditionally, the spin chute control panel shown, in Figure 3, replaced the production armament control panel on the left main instrument sub-panel. An over-the-shoulder video camera was mounted on the bulkhead aft of the pilot's left shoulder. A gaseous oxygen tank, mounted in the aft cockpit, replaced the production $\mathrm{T}-45 \mathrm{~A}$ on-Board oxygen Generating system (OBOGS) to provide the pilot with an uninterrupted flow of oxygen in the event of an engine Propulsion and electrical modification to provide each engine splitting the electrical services but with a single battery and to provide independent power sources for the spin chute system. Continuous ignition was available when the back-up fuel system was selected. 


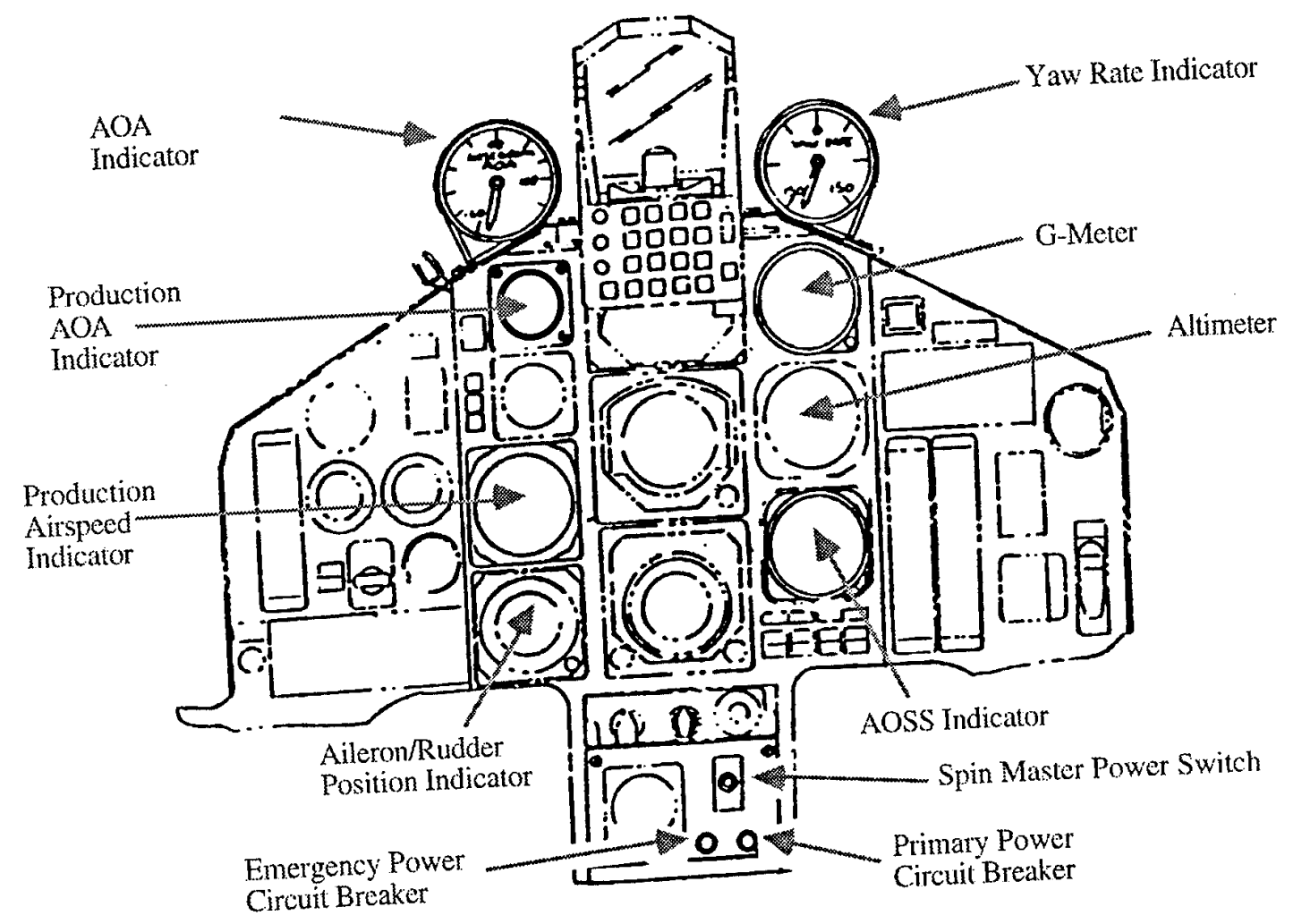

Figure 2. Forward Cockpit Main Instrument Panel Configuration.

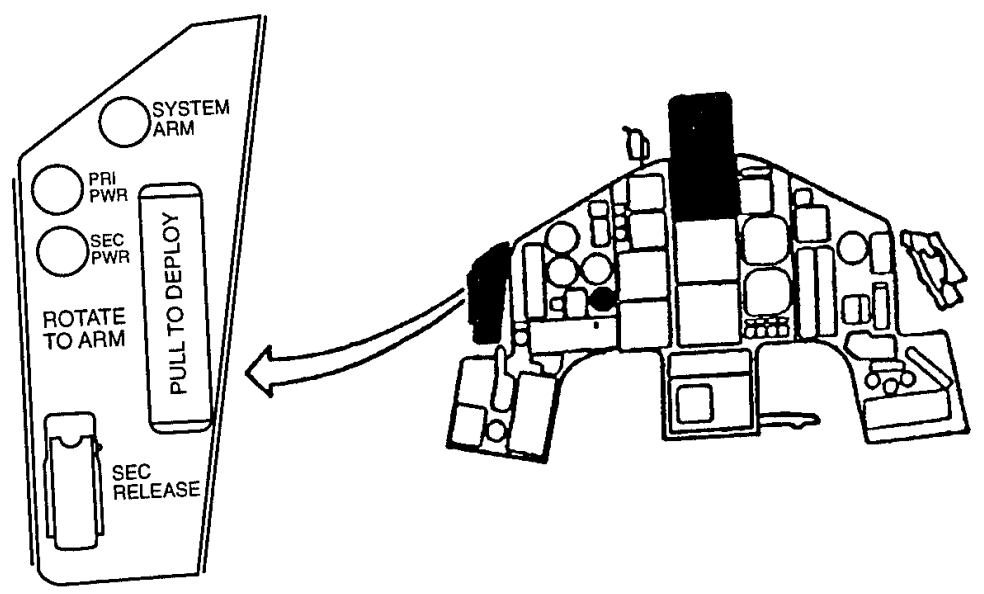

Figure 3. Spin Chute Control Panel. 
The modified electrical system had demonstrated 30 minutes of available electrical power and allowed continuous monitoring via telemetry during engine-out operation.

The fuel system was instrumented and data were displayed to the pilot and ground station to monitor potential fuel imbalances. Production fuel system demonstrated an inverted flight capability for 60 seconds at IDLE power.

The hydraulic system was modified by the installation of two additional hydraulic accumulators in the HYD 2 (flight control) system. The speed brake was moved from the HYD 1 to the HYD 2 system as it was predicted to have a significant impact on spin recovery. These complementary accumulators provided at least five full control stick cycles and one speed brake retraction without hydraulic pressure provided by the ram air turbine.

The spin chute system, (see Figure 4) was a modification of the normal brake chute of the BAe HAWK designed for a maximum deployment speed of 158 KEAS. The normal tailhook attach point was used for the spin chute attachment point through the use of a parachute beam structure.

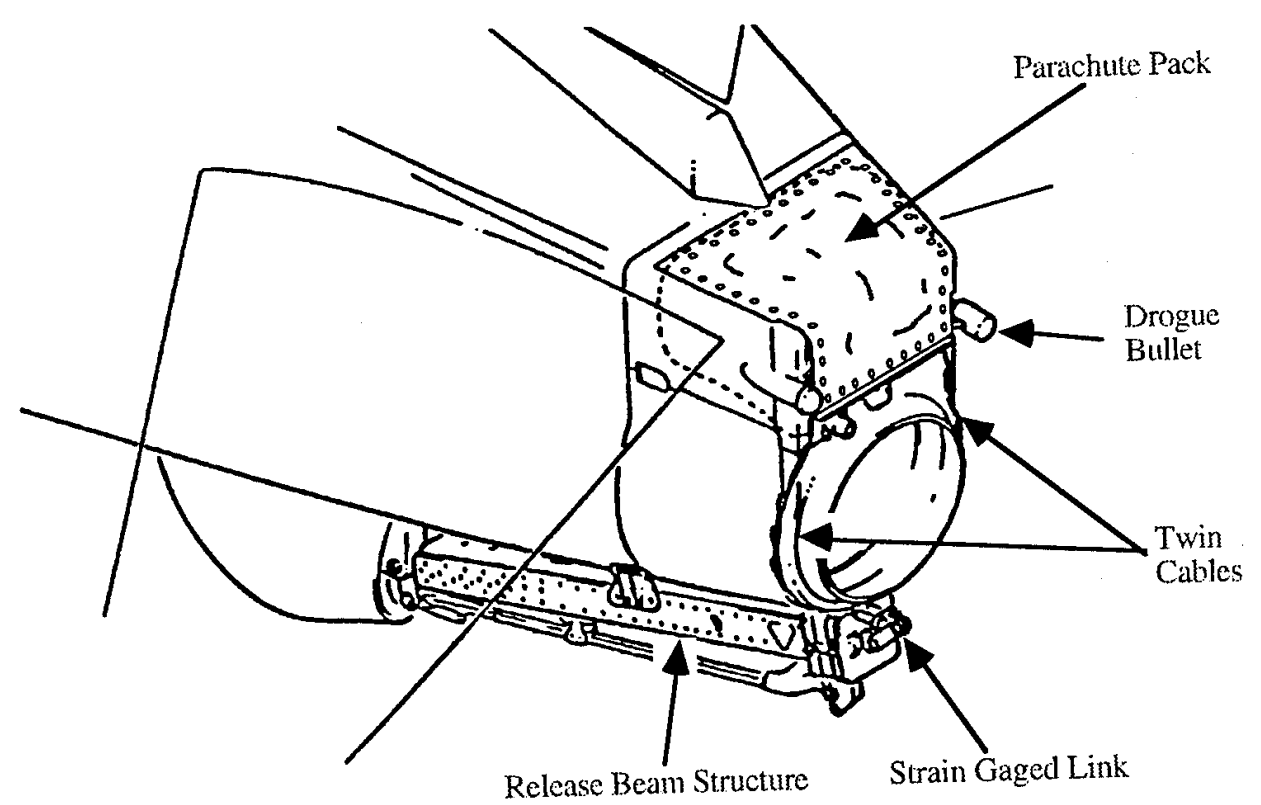

Figure 4. Spin Chute Installation.

There were two spin chute release systems: a mechanical system as the primary and the back-up method by an explosive bolt. The spin chute system was fully instrumented and chute

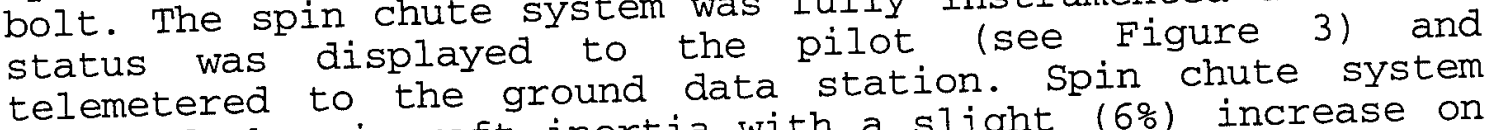
affected the aircraft inertia with a slight (6\%) increase on $I_{x}$ and $I_{y}$ and was predicted to negligibly affect the aircraft aerodynamically. As a result of the structural failure of the 
spin chute during the April 7, 1993 delayed recovery the steel cables were changed to kevlar straps and were layerpacked vice packed in an interwoven coil.

\section{BUILD-UP}

Prior to initiation of flight test, test team training was conducted. Three pilots, two from NAWC-AD and one from the contractor, were identified to fly the HAOA tests. Navy pilots were acclimated to the inverted environment by flying inverted spins in the T-2C. Pilots traveled to Naval Air station Kingsville, Texas to use the training command simulators to become comfortable with engine-out and all airstart procedures at a variety of attitudes and altitudes, primarily those inverted near the ejection altitude. With the high probability of engine-out operations, training flights were dedicated to conducting simulated flameout approaches. Team training was also conducted at $\mathrm{MDA}$, St. Louis, Missouri. Training consisted of engineering analysis briefings, test procedures and conduct, and data-room-controlled flight profiles using the manned-flight-simulator. This training allowed the pilots to become familiar with the communication procedures, entry procedures, spin identification and recovery. The simulated test flights allowed the test team to operate together and to become familiar and comfortable with each other.

Once located at Edwards AFB, California, all pilots flew two to three HAOA build-up flights that involved several engine shutdowns and airstarts, a series of benign departures $\left(180^{\circ}\right.$ bank-to-bank rolls using a variety of control inputs and $\mathrm{MaCh})$, and upright spirals (+30 mode). The build-up allowed the pilots to become re-acquainted with the test procedures, departure characteristics, and the disorienting nature of departure testing.

\section{ASSUMPTIONS GOING INTO FLIGHT TEST}

There was extensive engineering support required for the HAOA test program. Using rotary balance wind tunnel data and the six degree-of-freedom simulation, inverted spin recovery procedures were identified. Manned flight simulations were conducted throughout the engineering phase to refine and verify recovery controls. As a result, the following assumptions were made:

- Two stable inverted spin modes $\left(-60^{\circ}\right.$ and $-25^{\circ}$ modes) and two oscillatory divergent upright spin modes $\left(+45^{\circ}\right.$ and $+30^{\circ}$ modes) existed.

- Spin mode transitions were not likely with a clean airplane except from upright to inverted. 
- Stable inverted spiral $\left(-25^{\circ}\right.$ mode) was highly improbable in a clean wing configuration.

- Inverted spiral to inverted spin transition was not likely with a symmetrically loaded airplane.

- Neutral controls in a spiral would lead to recovery without spin mode transition.

- Pilot could center rudder pedals during recovery from all spin modes however this would take a considerable amount of force (approximately $250 \quad 1 b_{f}[1,100 \mathrm{~N}]$ ).

- Expect an engine anomaly resulting in a flameout or locked-in surge requiring the engine to be shutdown and a subsequent engine relight. Relight reliability to date had been $100 \%$.

Since the analysis demonstrated that the T-45A favored the inverted spin mode, our testing primarily targeted the inverted spin modes. The plan was to begin testing with the inverted spin to validate the recovery technique while at the highest possible altitude. This was necessary to achieve confidence in the recovery procedures in case other departures or spins transitioned to inverted spins at lower altitudes.

\section{INVERTED SPINS}

The inverted spins were entered at low Mach (0.43 IMN), $8^{\circ}$ to $16^{\circ} \mathrm{AOA}$ and at approximately $33,000 \mathrm{ft}(10,000 \mathrm{~m})$ pressure altitude in the clean configuration with the speed brakes retracted, the YDC engaged, and IDLE power setting. The inverted spin was entered through a timed $1-\mathrm{g}$ crosscontrolled departure. After $270^{\circ}$ of roll, varying the final control position determined the spin mode. Successful inverted spin entry was highly dependent upon proper control input timing. With a successful entry, spins were maintained for approximately three turns followed by the flight manual recovery control application. If not recovered by $18,000 \mathrm{ft}$ $(5,500 \mathrm{~m})$ pressure altitude the spin chute was to be deployed. If no signs of recovery were evident by $12,000 \mathrm{ft}$ $(3,660 \mathrm{~m})$ pressure altitude $(10,000 \mathrm{ft}[3,050 \mathrm{~m}]$ above ground) the pilot would initiate ejection.

From the pilot's perspective, the T-45A appeared to enter a cartwheel-like motion in the initial stages of the cross-control departure. The pilot's natural tendency, since there was no steady state motion, was to neutralize the controls due to the disorienting post stall gyration (PSG) and early stages of the spin. In addition to the disorientation of inverted spin entry, the high $\mathrm{AOA}$ and high sideslips encountered distorted the smooth airflow into the 
inlet which usually produced an engine anomaly, flame-out or locked-in surge requiring the engine to be shutdown during the spin. Fortunately, the engine relights were 100\% successful. The inverted spiral entry however, was less disorienting to the pilot than the spin entries due to the lack of any large PSG. Once in the steady state spin, the airplane motions were neither disorienting nor uncomfortable.

Three developed inverted spin modes where encountered during testing: $-60^{\circ},-40^{\circ}$ and $-25^{\circ}$ (inverted spiral). A summary of the inverted spin characteristics are presented in Table 1.

Table 1 Inverted Spin Mode Characteristics*

\begin{tabular}{|l|c|c|c|}
\hline \multirow{2}{*}{ Spin Parameters } & \multicolumn{3}{|c|}{ Spin Mode } \\
\cline { 2 - 4 } & $-60^{\circ}$ Mode & $-40^{\circ}$ Mode & $-25^{\circ}$ Mode \\
\hline \hline Average AOA (deg) & -60 & -40 & -25 \\
\hline AOA Range (deg) & -50 to -70 & -30 to -60 & -5 to -40 \\
\hline Average Sideslip (deg) & -15 & -15 & -15 \\
\hline Sideslip Range (deg) & -40 to 40 & -40 to 10 & -35 to -5 \\
\hline $\begin{array}{l}\text { Average RolI Rate } \\
\text { (deg/s) }\end{array}$ & -60 & -75 & -120 \\
\hline Roll Rate Range (deg/s) & -50 to -70 & -70 to -80 & $\begin{array}{c}-110 \text { to } \\
-130\end{array}$ \\
\hline Average Yaw Rate (deg/s) & 95 & 75 & 45 \\
\hline Yaw Rate Range (deg/s) & 85 to 130 & 70 to 80 & 35 to 55 \\
\hline Pitch Attitude (deg) & -20 to -70 & -20 to -70 & -80 to -50 \\
\hline $\begin{array}{l}\text { Indicated Airspeed } \\
\text { (KIAS) }\end{array}$ & 50 to 120 & 100 to 160 & 140 to 200 \\
\hline Seconds per Turn & 3.0 & 3.5 & 3.5 \\
\hline $\begin{array}{l}\text { Altitude Loss per Turn } \\
\text { (ft [m]) }\end{array}$ & 1,000 & $\begin{array}{c}1,000 \\
{[305]}\end{array}$ & $\begin{array}{c}1,700 \\
{[520]}\end{array}$ \\
\hline
\end{tabular}

* Sideslip, roll rate, and yaw rate values are for a right spin. Reverse the sign for a left spin.

Al1 the inverted spin modes maintained a load factor of -1.0 to $-1.4 \mathrm{~g}$ with the turn needle pegged and the production $A O A$ indicator pegged at 1 unit (the production gauge ranged from 1 to 29 units). Once in a steady state spin, all inverted modes were oscillatory about all three axes, although the inverted spiral was much less oscillatory.

with the rudder deflected in the pro-spin direction (in the direction of the turn needle) the airplane entered the $-40^{\circ}$ and $-60^{\circ}$ modes. The lateral stick determined the sustained spin mode: $-40^{\circ}$ with the lateral stick at neutral and $-60^{\circ}$ mode with the lateral stick held in pro-spin direction. The nose attitude varied between $20^{\circ}$ and $70^{\circ}$ below the horizon in a smooth oscillation. The primary pilot indication of spin mode was airspeed. The $-60^{\circ}$ mode oscillated between 50 and 120 KIAS compared to 100 to 160 
KIAS in the $-40^{\circ}$ mode. Occasionally, while maintaining full pro-spin controls, the T-45A would oscillate out of the spin. The inverted spiral $\left(-25^{\circ}\right.$ mode) was entered in one of two ways: transitioning from either the $-60^{\circ}$ or $-40^{\circ}$ modes or through the direct entry (cross-control departure followed by neutral rudder pedal after $270^{\circ}$ of roll and maintaining lateral stick). Unfortunately, anti-spin control inputs were pro-spiral controls which led to the spin mode transition. During testing, an inverted spiral could not be sustained with neutral lateral stick.

Pilot indication of the spiral were the same as those for the spin except that the airspeed ranged from 140 to 200
KIAS, with an incipient $-25^{\circ}$ mode at 140 to 160 KIAS and a fully developed spiral above 160 KIAS. Airspeed in the spiral was oscillatory, slowly increasing to near 200 KIAS and then began to decrease. The inverted spiral exhibited more rolling motion and was slightly more disorienting and uncomfortable than did the other spin modes. The inverted spiral produced the steepest average nose attitudes $\left(50^{\circ}\right.$ to $80^{\circ}$ below the horizon) of all the modes. To the pilot, the airplane appeared to fly sideways as large side forces developed with loud canopy wind noises.

\section{INVERTED SPIN RECOVERY}

During testing, spin recovery was commanded by using one of two procedures and included several misapplied controls to determine their effects on recovery. In the first method, recovery from either of the higher negative $A O A$ inverted spins was accomplished by applying full rudder pedal and full lateral stick opposite the spin direction. Recovery usually occurred within two turns if the sideslip was oscillatory; however, with steady sideslip, prolonged recoveries or transition into the $-25^{\circ}$ mode occurred. Holding the pedal in the anti-spin direction was at times very difficult due to the high sideslip forces acting on the rudder, requiring over $2501 b_{f}(1,110 \mathrm{~N})$ pedal force to achieve only neutral rudder. Full anti-spin rudder was not required for spin recovery, however, maintaining high rudder deflection caused quicker recoveries. The initial flight manual recovery procedure was to maintain the anti-spin control inputs until recovery or 160 KIAS, which ever came first, then neutralize all controls. After the first few flights, it was obvious that centering the rudder pedals sometimes defeated the no-float rudder centering mechanism when the pilot inadvertently applied a small differential pedal force favoring the prospin side. The rudder would then be forced by sideslip in the pro-spin direction (rudder blow-out) and the airplane would transition to the $-40^{\circ}$ mode resulting in delayed recoveries. stable pro-spin sideslip was an excellent indication of 
potential rudder blow-out. Characteristics of the inverted spin recovery using the initial flight manual procedures are listed in Table 2 .

Table 2

Inverted Spin Recovery Characteristics Using The Flight Manual Procedure

\begin{tabular}{|l|c|c|}
\hline \multirow{2}{*}{ Recovery Parameters } & \multicolumn{2}{|c|}{ Spin Mode } \\
\cline { 2 - 3 } & $-60^{\circ}$ Mode & $-25^{\circ}$ Mode \\
\hline \hline Spins Achieved & 18 & 2 \\
\hline Average Turns to Recover & 4 & 3 \\
\hline Maximum Turns to Recover & 9 & 6 \\
\hline $\begin{array}{l}\text { Rudder Blow-outs During } \\
\text { Recovery }\end{array}$ & 3 & 1 \\
\hline Engine Anomalies & 17 & 0 \\
\hline
\end{tabular}

In one instance, rudder blow-out caused mode transition delaying recovery to just under 18,000 ft $(5,500 \mathrm{~m})$ pressure altitude. The initial recovery procedure was determined to be unsatisfactory due to the inconsistencies of the recoveries from the inverted spin modes.

The test team then elected to modify the flight manual procedures. The new procedure was similar to the old procedure except that the pilot maintained anti-spin rudder pedal until recovery was complete rather than forcefully centering the pedals at 160 KIAS. Characteristics of the inverted spin recovery using the modified procedures are listed in Table 3 .

Table 3

Inverted Spin Recovery Characteristics Using A Modified Flight Manual Procedure

\begin{tabular}{|l|c|c|c|}
\hline \multirow{2}{*}{ Recovery Parameters } & \multicolumn{3}{|c|}{ Spin Mode } \\
\cline { 2 - 4 } & $-60^{\circ}$ Mode & $-40^{\circ}$ Mode & $-25^{\circ}$ Mode \\
\hline \hline Spins Achieved & 30 & 38 & 11 \\
\hline Average Turns to Recover & 1.5 & 2.0 & Less than 1 \\
\hline Maximum Turns to Recover & 4 & 6 & 2 \\
\hline $\begin{array}{l}\text { Rudder Blow-outs During } \\
\text { Recovery }\end{array}$ & 0 & $2 *$ & 0 \\
\hline Engine Anomalies & 29 & 33 & 0 \\
\hline
\end{tabular}

* Rudder blow-outs were due to inadvertent pro-spin rudder pedal force.

The modified recovery procedure provided more consistent recoveries than the original procedure. There was a beneficial reduction in rudder blow-outs when the pilot held 
anti-spin rudder pedal force until recovery was confirmed (airspeed greater than 160 KIAS and AOA greater than 5 units). Recoveries from the inverted spin modes using the modified recovery procedure required one to three turns and spin mode transitions, due to rudder blow-out, were eliminated. There was no tendency for a progressive spin with the anti-spin rudder held too long.

Anti-spin lateral stick for the $-60^{\circ}$ and $-40^{\circ}$ modes was pro-spin for the $-25^{\circ}$ mode. Recovery from the $-25^{\circ}$ mode was accomplished by neutralizing lateral stick and maintaining anti spin rudder pedal until recovery. These control inputs would cause the T-45A to recover immediately or enter a PSG and subsequent recovery.

The initial test plan included evaluation of inverted spins with lateral asymmetries up to $2,500 \mathrm{ft}-1 \mathrm{~b}_{\mathrm{f}}(3,390$ $\mathrm{N}-\mathrm{m})$. The test team abandoned the plan when the aircraft exhibited delayed recoveries (more than four turns) with small fuel asymmetries from two $-40^{\circ}$ modes and one $-60^{\circ}$ mode. Fuel asymmetry was approximately 100 lb $(45 \mathrm{~kg})$. Characteristically, the asymmetrical inverted spins were less oscillatory with the average AOA, sideslip, and yaw rate achieving higher steady state values. For example, a $-40^{\circ}$ mode spin with an asymmetry looked remarkably similar to a non-asymmetrically loaded $-60^{\circ}$ mode.

\section{CROSS-CONTROL DEPARTURES}

Spin susceptibility was evaluated during cross-control departures between 0.4 and 0.5 IMN at 33,000 ft $(10,000 \mathrm{~m})$ pressure altitude using a variety of speed brake extensions, YDC options, and misapplied controls. Entry into the departures was accomplished using the same method as the inverted spin entry except the controls input were held for $360^{\circ}$, at which time the controls were neutralized or the desired misapplied controls were introduced. For departures that entered a PSG, neutral lateral stick and rudder pedals forcefully centered recovered the T-45A. These PSG's were very dynamic with oscillatory $\mathrm{AOA}$ (peaking at $\pm 80^{\circ}$, usually negative) and sideslip $\left( \pm 50^{\circ}\right)$. Roll rates ranged from 100 to $300 \mathrm{deg} / \mathrm{s}$ and yaw rates of 80 to $120 \mathrm{deg} / \mathrm{s}$. Motions similar to that were seen during the inverted spin entries with the pilot feeling the effects of the $\pm 1.5 \mathrm{~g}$ normal and lateral accelerations. More dynamic departures were obtained at higher entry Mach with the YDC disengaged and the speed brake extend. Recovery time was inconsistent with some departures lasting as long as 20 seconds. Rudder position was more critical than lateral stick inputs during the recovery. Rudder blow-out was common and often resulted in a $-40^{\circ}$ mode spin entry if the pilot was unable to counter the pedal force to maintain or move the rudder to neutral. Summary of the cross-control departures are shown in Table 4. 
Table 4

Cross-Control Departure Summary

\begin{tabular}{|l|c|c|c|c|}
\hline Recovery Control During Departure & $\begin{array}{c}\text { Entry } \\
\text { Mach } \\
\text { (TMN) }\end{array}$ & $\begin{array}{c}\text { Number } \\
\text { Flown }\end{array}$ & $\begin{array}{c}\text { Rudder } \\
\text { Blow } \\
\text { Out }\end{array}$ & $\begin{array}{c}-40^{\circ} \text { Spins } \\
\text { Entered* }\end{array}$ \\
\hline \hline Neutral Stick, Pedals Centered & 0.50 & 2 & 2 & 1 \\
\hline Neutral Stick, Pedals Centered & 0.43 & 8 & 1 & 1 \\
\hline Neutral Stick, Pedals Free & 0.43 & 3 & 3 & 2 \\
\hline $\begin{array}{l}\text { Pro-Spin Lateral stick, Rudder } \\
\text { Centered }\end{array}$ & 0.43 & 4 & 3 & 3 \\
\hline Aft stick, Rudder Centered & 0.43 & 2 & 1 & 1 \\
\hline
\end{tabular}

* All departures that resulted in a $-40^{\circ}$ spin mode were cases where rudder blow-out occurred.

\section{UPRIGHT SPINS}

There were two upright spin modes, the $+45^{\circ}$ (spin) and $+30^{\circ}$ (spiral) modes. Both spin modes were oscillatory divergent. The upright spin entry was very difficult due to the precise timing required. Two attempts to intentionally enter the upright spin were unsuccessful with one attempt achieving a $300 \mathrm{deg} / \mathrm{s}$ roll rate which exceeded the aircraft structural placard of $270 \mathrm{deg} / \mathrm{s}$. Previous testing indicated the airplane was resistant to the upright spin. Considering the susceptibility to the upright spin to be low and due to the possibility of exceeding the roll rate structural limit, the test team discontinued the upright spin $\left(+45^{\circ}\right.$ mode) evaluation.

The $+30^{\circ}$ mode (upright spiral) was evaluated for use as a potential out-of-control flight training maneuver. The goal was to identify the useful maneuver abort criteria, departure resistance, and engine anomalies. The spiral was commanded by applying full rudder pedal, full aft stick, and maintaining neutral lateral stick at the same entry conditions and configurations as the cross-control departure. Typical spirals presented the pilot with comfortable and predictable spin-like indications that were characterized by a slow yaw rate $(30 \mathrm{deg} / \mathrm{s}, \pm 15 \mathrm{deg} / \mathrm{s})$ and gradual airspeed increase $(+10 \mathrm{kt}$ per turn). Roll rate was oscillatory (50 to 100 $\mathrm{deg} / \mathrm{s})$ and as airspeed increased, the magnitude of the oscillations increased without a tendency to depart. Larger oscillations occurred with the YDC off and the speed brakes extended. Recovery from the $+30^{\circ}$ mode was immediate with the application of neutral controls. No flameouts, locked-in surges or pop surges were experienced during typical upright spirals.

Lateral stick inputs applied in the same direction as the rudder during the spiral increased the roll oscillations. Insidious (smooth) application of lateral stick opposite the rudder (cross-control) generally resulted in a departure and entry into an inverted spin (typically the $-40^{\circ}$ mode). On one 
occasion, the spiral initially progressed as expected; however, the airplane transitioned into an upright spin $\left(+45^{\circ}\right.$ mode), then suddenly departed in roll, causing a locked-in engine surge. Considering the engine anomalies and departures with misapplied controls, the test team determined the upright spiral was unsuitable as an out-of-control flight training maneuver.

\section{TEST RESULTS}

The goals of the flight test were three fold: (1) validate the $\mathrm{T}-45 \mathrm{~A}$ flight manual departure and spin recovery procedures, (2) evaluate the T-45A departure and spin characteristics, and (3) evaluate the departure and spins for use as potential out-of-control flight training maneuvers. With the airplane safe-on-deck and the data analyzed, the test team made the following conclusions:

- The initial flight manual departure and spin recovery procedure provided inconsistent recoveries from the inverted spin by allowing the rudder to blow-out in the pro-spin direction resulting in spin mode transitions and delayed recoveries. The procedure was modified by holding anti-spin rudder pedal force until recovery was confirmed, thus reducing rudder blow-outs in the pro-spin direction and eliminating mode transition.

- Initial engineering analysis determined that there were only two stable inverted spin modes at $-25^{\circ}$ and $-60^{\circ}$ AOA. Flight test discovered a third stable inverted spin mode at $-40^{\circ} \mathrm{AOA}$.

- Although testing was to include asymmetric loading out to $2,500 \mathrm{ft}-1 \mathrm{~b}_{\mathrm{f}}(3,390, \mathrm{~N}-\mathrm{m})$, small fuel asymmetries will aggravate the spin characteristics and delay recovery.

- The T-45A was susceptible to inverted spins following cross-control departures when the pilot was unable to maintain centered rudder.

- There were no spins that could be used as out-ofcontrol flight training maneuvers due to the susceptibility of inverted spins, inconsistent inverted spin recoveries, and engine flame-outs. Although the upright spiral was the most promising if done correctly, susceptibility to departure and engine anomalies when controls were misapplied rendered it unsuitable. 


\section{IESSONS LEARNED}

Visibility and management scrutiny was high during flight test as is common for all high $A O A$ test programs. Test team coordination was excellent and provided a technically sound approach to the high risk flight test program. Constant engineering analysis of the flight test data was conducted throughout the testing to track potential problem areas and to allow adjustments to the game plan. Testing was suspended twice for delayed recoveries and unanticipated inverted spin mode transitions. The first interruption occurred when the T-45A failed to recover from an incipient inverted spiral and transitioned into the $-40^{\circ}$ mode prior to recovery. The second stoppage was the result of multiple inverted spin mode transitions which excessively delayed recovery. On both occasions extensive data review was conducted, to mitigate the risks of continuing, prior to the decision to resume flight test.

Teamwork was the key to the successful completion of the HAOA program. Although there was some temptation for the team members to align themselves with their employer, the test team remained together and did what was necessary to complete the mission. The important lessons learned were the same lessons taught from day one:

- Don't take anything for granted. Plan for the unexpected: engine flameouts, delayed recoveries, spin chute deployment, and the need for back-up systems ;

- If something doesn't look right . . . stop! . . and don't be afraid to modify the test plan;

- Don't be persuaded to go down the wrong path, and finally;

- Manage your risks.

From a negative standpoint, the spin chute was designed to a maximum of $158 \mathrm{KEAS}$ and there were occasions when the T-45A was out-of-control at 190 KIAS. Although the risks were thought to be minimal, there were no guarantees that the spin chute would be effective throughout the departure and spin envelope. 


\section{SUMMARY}

This HAOA program had its exciting and eventful flights. The entire process, from engineering analysis and team training, through flight test, was challenging and rewarding. Success was due to the hard work and dedication of T-45A HAOA Test Team: engineers, pilots, aircraft maintainers and support personnel. Hopefully, the lessons learned and technical analysis used in the T-45A HAOA test program will help future high angle-of-attack programs. 